\title{
Induction Motors Condition Monitoring System with Fault Diagnosis Using a Hybrid Approach
}

\author{
Hong-Chan Chang *, Yu-Ming Jheng, Cheng-Chien Kuo and Yu-Min Hsueh \\ Department of Electrical Engineering, National Taiwan University of Science and Technology No.43, \\ Keelung Rd., Sec.4, Da'an Dist, Taipei 10607, Taiwan; 100m05001@stud.sju.edu.tw (Y.-M.J.); \\ cckuo@mail.ntust.edu.tw (C.-C.K.); D10307009@mail.ntust.edu.tw (Y.-M.H.) \\ * Correspondence: hcchang@mail.ntust.edu.tw; Tel.: +886-2737-6677
}

Received: 17 March 2019; Accepted: 9 April 2019; Published: 18 April 2019

\begin{abstract}
This study develops a condition monitoring system, which includes operating condition monitoring (OCM) and fault diagnosis analysis (FDA). The OCM uses a vibration detection approach based on the ISO 10816-1 and NEMA MG-1 international standards, and the FDA uses a vibration-electrical hybrid approach based on various indices. The system can acquire real-time vibration and electrical signals. Once an abnormal vibration has been detected by using OCM, the FDA is applied to classify the type of faults. Laboratory results indicate that the OCM can successfully diagnose induction motors healthy condition, and FDA can classify the various damages stator fault, rotor fault, bearing fault and eccentric fault. The FDA with the hybrid approach is more reliable than the traditional approach using electrical detection alone. The proposed condition monitoring system can provide simple and clear maintenance information to improve the reliability of motor operations.
\end{abstract}

Keywords: operating condition monitoring; fault diagnosis analysis; hybrid approach

\section{Introduction}

Taking a large power plant in Taiwan as an example, each of its large thermal generator sets relies on an auxiliary system with numerous high-voltage motors for operation. The elements of the auxiliary system for the generator sets-which includes fans, coal pulverizers, gearboxes, fluid couplings, and conveyor belts-are all driven by high-voltage motors, and these motors often require operation under specialized conditions. Any breakdown in the auxiliary system not only affects the power quality and reliability of the entire power system, but it can also result in enormous economic losses. Thus, the importance of condition monitoring and fault diagnosis of induction motors in auxiliary systems cannot be underestimated.

Various damage types were found, such as interturn short-circuit [1], broken rotor bar [2], bearing inner ring failure, bearing outer ring failure, ball failure, cage failure [3], and eccentricity [4]. As for fault diagnosis of an induction motor, the literature has also indicated that approximately $30 \%$ of motor breakdowns are related to stators, $10 \%$ to rotors, $40 \%$ to bearings, and $20 \%$ to other components [5].

A great deal of research proposes how to classify the damage types, such as stator breakdowns, and have employed various approaches [6-12], including magnetic pendulous oscillation, motor current signature analysis, instantaneous active and reactive power signature analyses, and total harmonic voltage. Studies on rotor breakdowns [13-16] have used mathematical morphology and wavelet analysis. Bearing breakdowns have been investigated using the root-multiple signal classification method and neural networks $[17,18]$. As for breakdowns in other components, recent studies focused on the relatively more common eccentricity problems, which were examined in References [19-22]. 
Recently, a motor diagnosis manner was generally used in industries, which is called time-based maintenance (TBM) [23]. The TBM is maintenance performed on equipment based on calendar schedules. This means that the schedules will be important for routine maintenance. However, the TBM may result in over maintenance to prevent considerable waste of manpower and resources.

In industry 4.0, thriving developments in the sensor, communication, and information processing industries have gradually made the real-time online monitoring of motors a real possibility. The latest trend in motor maintenance is thus condition-based maintenance (CBM), which is effective in accident prevention. CBM also allows motors to remain reliable throughout their service time [23]. Thus, it is critically important to develop a condition monitoring system with fault diagnosis using a vibration-electrical hybrid approach system for induction motors based on CBM.

\section{Hardware Architecture}

\subsection{Overall Structure}

Most condition monitoring systems (CMS) worldwide that are currently used for monitoring important motors have a hierarchical structure. Figure 1 depicts such a system, the front end of which consists of small, inexpensive, reliable, fast, and simply constructed data acquisition/transmission devices, embedded in crucial equipment on site, and the back end of which is a monitoring system. Relay stations may be installed between the front and back ends due to distance or data transmission considerations. Relay stations must have high expandability and flexibility to allow effective and timely presentation of motor conditions to on-site operators at the front end and long-term recording of operating data at the back end. Additionally, the system should be able to perform trend analyses based on longitudinal data stored in its database. The study develops condition monitoring with fault diagnosis embedded system in the front end.

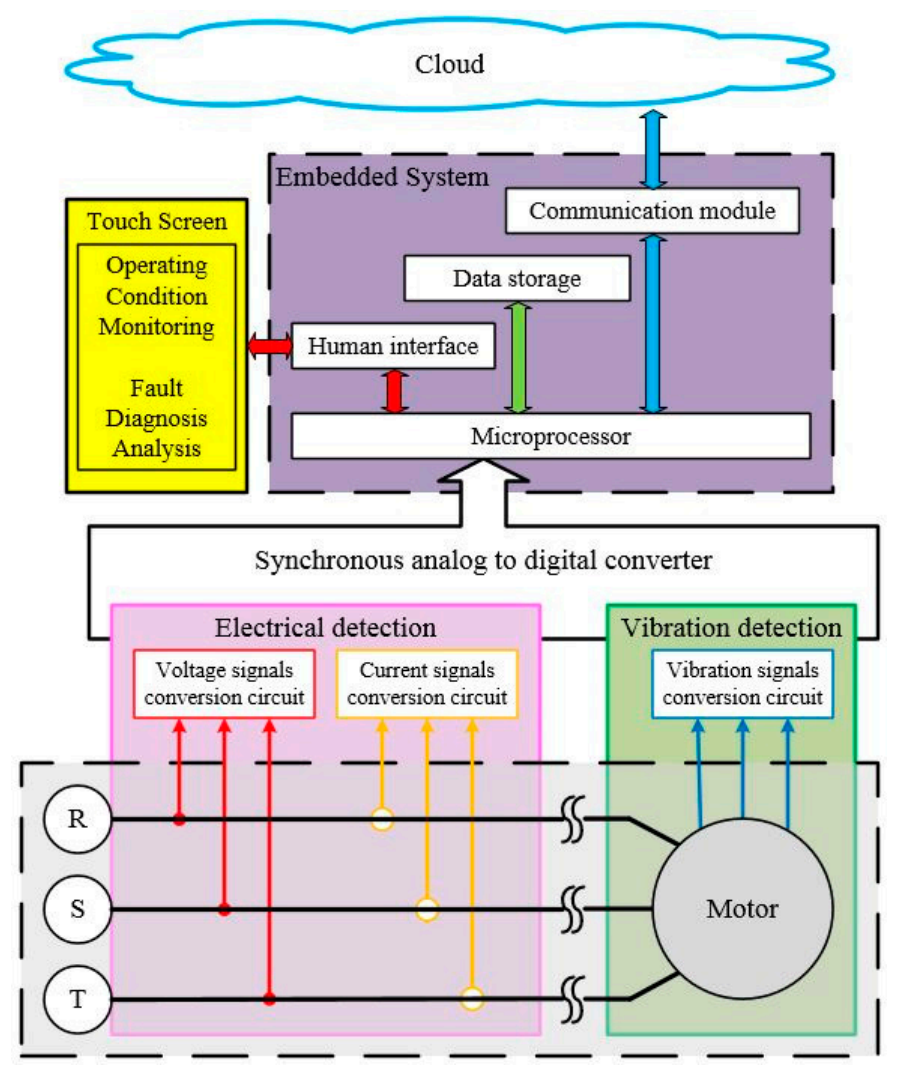

Figure 1. Overall system diagram. 
In Figure 2, a simple embedded system is proposed for condition monitoring and fault diagnosis of induction motors. The front end embedded system prototype size is $240 \times 170 \times 30 \mathrm{~mm}$. The system assesses the current condition of a motor through vibration detection. When an abnormality is detected, electrical detection is used in conjunction with vibration detection to determine the possible type of fault. This system adopts a triaxial accelerometer to measure the vibration of the motor, non-contact capture of voltage, and current signals using Hall sensors. The acquired analog signals are passed through a signal processing circuit and transmitted to an analog-to-digital converter, which converts them into digital signals and passes them on to a microprocessor for processing. Subsequently, fast-screening fault diagnosis and fast-screening condition monitoring are employed, and the results are displayed on the touchscreen in simple and intuitive graphics. If intranet is available on site, the original signal data can be transmitted to the server-side system, which will make the system operations even more comprehensive by conducting rigorous analyses. If intranet is not available, the original data can be transported using a secure digital (SD) card to a computer for further analysis. As a means of data transportation, the SD card and intranet are not mutually exclusive; the choice between the two depends solely on the availability of on-site intranet.

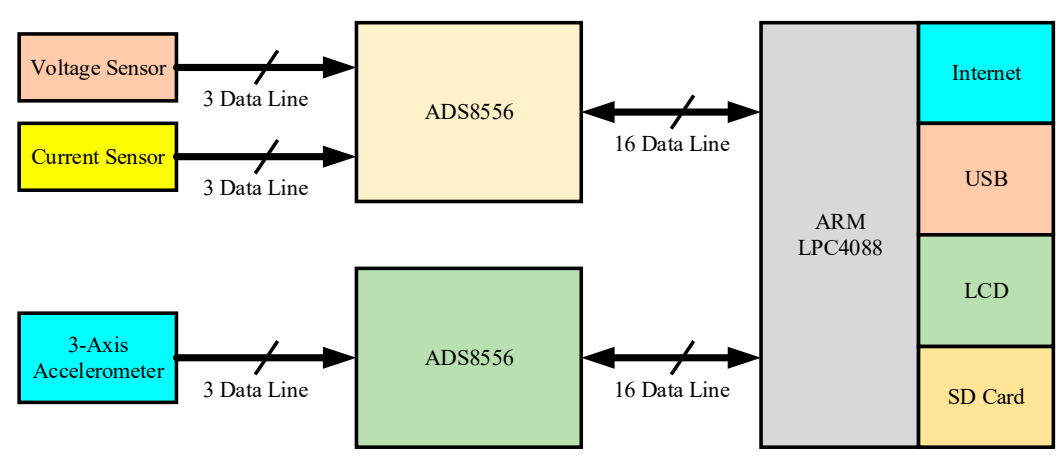

Figure 2. Front-end embedded system block diagram.

\subsection{Sensor Modules}

The voltage and current sensors are used in this study were all Hall devices because of their high safety and convenience. A triaxial accelerometer is used to measure accelerations along the three axes, and its sensor is an integrated electronics piezoelectric (IEPE) circuit. Such sensors have sensitive built-in charge or voltage amplifiers because the current generated by the accelerometer is extremely weak, and that signal interference can easily occur in the sensors without such amplifiers. The IEPE transducer integrates these sensitive circuits and brings them close to the sensors to ensure greater noise immunity and easier packaging. The detailed sensor specifications are as listed in Table 1.

Table 1. Specifications of sensors.

\begin{tabular}{cccc}
\hline Sensors Model & Type & Measuring Range & Frequency Bandwidth \\
\hline Voltage Sensor & CHV 50P/600 & $0 \sim \pm 800 \mathrm{~V}$ & $0 \sim 20 \mathrm{kHz}$ \\
Current Sensor & HTR 50-SB & $0 \sim \pm 100 \mathrm{~A}$ & $0 \sim 10 \mathrm{kHz}$ \\
3-Axis Accelerometer & AD100T & $\pm 50 \mathrm{~g}$ & $0.3 \sim 12 \mathrm{kHz}$ \\
ADC & ADS8556 & $16 \mathrm{Bits}$ & $630 \mathrm{kSPS}$ (Parallel) \\
\hline
\end{tabular}

\section{Software Process}

\subsection{Overall Structure}

Figure 3 illustrates the process of the proposed hybrid approach. The CMS operations are divided into two major parts: Operating condition monitoring (OCM) and fault diagnosis analysis (FDA). When electrical and vibration signals have been acquired by the embedded system, the OCM module 
determines the current condition of the motor using vibration indices and international standards. When an abnormality is detected in the motor's operations, the system can classify the type of detected fault through vibration and electrical indices and simultaneously informs maintenance personnel of the components requiring attention. The system can reduce maintenance costs or advise maintenance personnel of the possible type of fault, thereby shortening the time needed for troubleshooting.

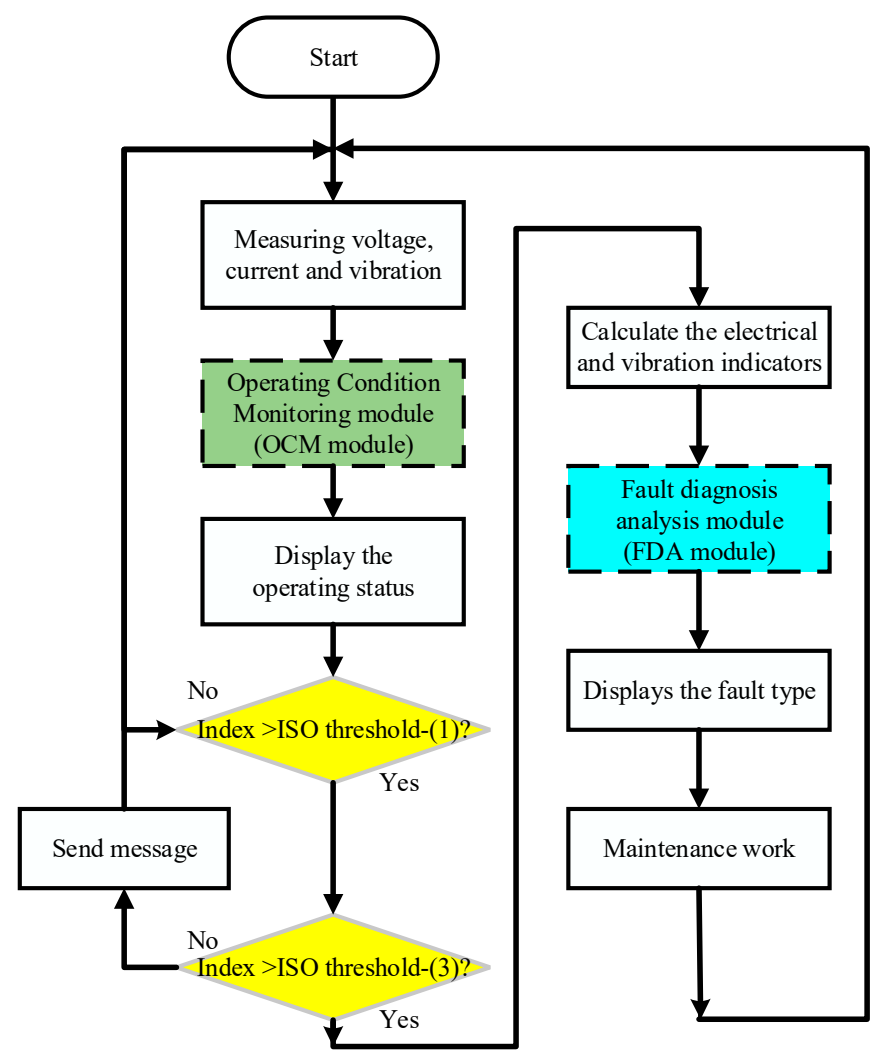

Figure 3. Overall hybrid approach flow chart.

\subsection{OCM Module}

OCM relies on existing international standards as the basis for its judgments. The international standards used are primarily the ISO 10816-1 [24], which regards velocity control (Table 2), and the NEMA MG-1 [25], which regards displacement control (Table 3).

Table 2. Thresholds by Std. ISO 10816-1.

\begin{tabular}{ccc}
\hline Velocity $(\mathbf{m m} / \mathbf{s})$ & Threshold & Class I $\leq \mathbf{1 5} \mathbf{~ W W}$ \\
\hline$<1.12$ & & Good \\
1.12 & ISO threshold-(1) & \\
$1.12 \sim 2.8$ & & Satisfactory \\
2.8 & ISO threshold-(2) & \\
$2.8 \sim 7.1$ & & Unsatisfactory \\
7.1 & ISO threshold-(3) & \\
$>7.1$ & & Unacceptable \\
\hline
\end{tabular}

Table 3. Thresholds by Std. NEMA MG-1.

\begin{tabular}{cc}
\hline Synchronous Speed (rpm) & $\begin{array}{c}\text { Thresholds } \\
\text { (Maximum Relative Shaft Displacement, Peak-peak) }\end{array}$ \\
\hline $1801-3600$ & 0.0028 in $(70 \mu \mathrm{m})$ \\
$\leq 1800$ & 0.0035 in $(90 \mu \mathrm{m})$ \\
\hline
\end{tabular}


Concerning the electrical detection method, although established international standards are available for the indices, comparable standards for the operations of motors are currently lacking. Hence, if the information currently at hand is to be used for the assessment of motor operating conditions, algorithms must be employed to perform the necessary calculations. However, this is an extremely time-consuming undertaking for microprocessors. For this reason, a fast-screening condition monitoring method is introduced instead. The method uses international standards on vibrations to assess the condition of motors. According to the motor's accelerations along the three axes, first-order integration is performed to obtain the velocity values to be compared with ISO 10816-1; subsequently, second-order integration is performed to obtain the displacement values to be compared with NEMA MG-1. Figure 4 describes the fast-screening process in more detail. Because ISO 10816-1 divides motor operations into four steps whereas NEMA MG-1 only has two steps, the method makes a logic judgment on the velocity and displacement comparison results and chooses the more serious ones for display in the system. The displayed results can be categorized into four levels: normal, caution, warning, and danger.

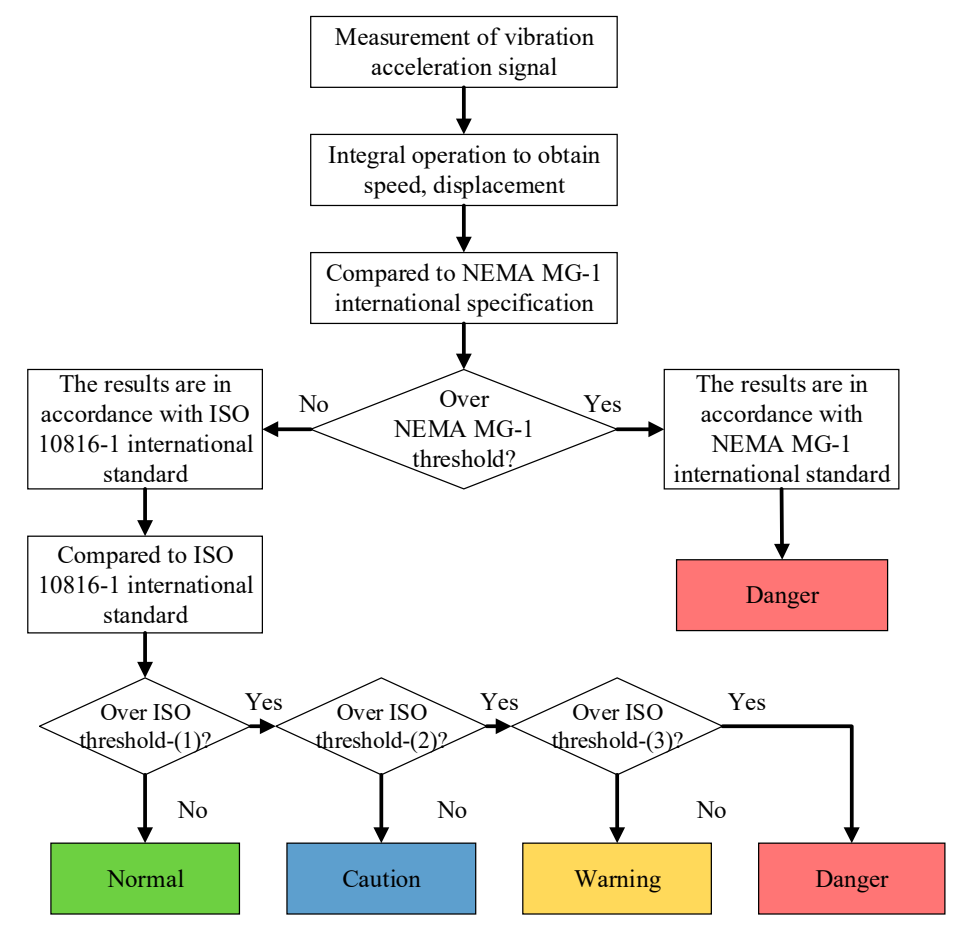

Figure 4. OCM module flow chart.

\subsection{FDA Module}

A two-stage hybrid approach for fault diagnosis analysis of induction motors is shown in Figure 5. The first stage of FDA uses vibration detection for preliminary classification of the faults. Numerous studies have been consulted to establish the indices for signal analysis, from which a small number of key signal indices for vibration acceleration are chosen for use [26].

The second stage of FDA involves using electrical detection to develop a more rigorous classification system of fault types on the basis of the electrical indices. The suitability of an electrical index to the detection of a fault type can be determined by observing the effect of each electrical index on the corresponding fault model.

1. Current unbalance rate (CUR): IEC 60034-1 [27] and IEEE Std. 141 [28] are used as a reference for the definition of CUR, which is similar to voltage imbalance rate; that is, it is the ratio of the three-phase current's maximum deviation value to its mean value. When the motor is operating 
at its rated output, it should avoid exceeding $10 \%$ of the recommended value, as indicated in the following equations:

$$
\begin{gathered}
\left|I_{\text {avg }}\right|=\frac{\left|I_{a}\right|+\left|I_{b}\right|+\left|I_{c}\right|}{3} \\
\operatorname{CUR}(\%)=\frac{\max \left(\|\left|I_{a}\right|-\left|I_{\text {avg }}\right|,|| I_{b}|-| I_{\text {avg }}||,|| I_{c}|-| I_{\text {avg }}|| \mid\right)}{\left|I_{\text {avg }}\right|} \times 100 \%,
\end{gathered}
$$

2. Current unbalance factor (CUF): IEC 60034-1 is used as a reference for CUF. Continuous operation of over $5 \%$ should be avoided:

$$
\begin{gathered}
{\left[\begin{array}{c}
I^{0} \\
I^{1} \\
I^{2}
\end{array}\right]=\frac{1}{3}\left[\begin{array}{ccc}
1 & 1 & 1 \\
1 & a & a^{2} \\
1 & a^{2} & a
\end{array}\right]\left[\begin{array}{c}
I_{a} \\
I_{b} \\
I_{c}
\end{array}\right], a=1 \angle 120^{\circ},} \\
\operatorname{CUF}(\%)=\frac{\left|I^{2}\right|}{\left|I^{1}\right|} \times 100 \% .
\end{gathered}
$$

3. Voltage total harmonic distortion (VTHD): IEEE Std. 519 [29] was used as a reference for VTHD, which is expressed as a percentage and defined as the square root of the sum of harmonic voltages divided by the fundamental frequency voltage, as shown in Equation (4). It is one of the means of assessing the total harmonic voltage's effect on the system.

$$
T H D_{V}=\frac{\sqrt{\sum_{h=2}^{\infty} V_{h}^{2}}}{V_{1}} \times 100 \% .
$$

4. Each voltage harmonic distortion (EVHD): IEEE Std. 519 is used as a reference for EVHD, which is defined as the percentage of the fundamental frequency voltage that is individual harmonic voltage, as shown in Equation (6). It is one of the means of assessing an individual harmonic voltage's effect on the system.

$$
\operatorname{VHD}(\%)=\frac{V_{h}}{V_{1}} \times 100 \% .
$$

5. Current total harmonic distortion (CTHD): IEEE Std. 519 is used as a reference for CTHD, which is expressed as a percentage and defined as the square root of the sum of harmonic currents divided by the fundamental frequency voltage, as shown in Equation (7). CTHD is used to assess the total harmonic current's effect on the system.

$$
\operatorname{THD}_{I}(\%)=\frac{\sqrt{\sum_{h=2}^{\infty} I_{h}^{2}}}{I_{1}} \times 100 \% .
$$

6. Each current harmonic distortion (ECHD): IEEE Std. 519 is used as a reference for ECHD. Defined in the same vein as EVHD, ECHD refers to the rate of an individual harmonic current's voltage to the fundamental frequency voltage. Expressed in percentage, this index serves as a means of assessing an individual harmonic current's effect on the system.

$$
\operatorname{IHD}(\%)=\frac{I_{h}}{I_{1}} \times 100 \%
$$

The suitability coefficient for an electrical index can be obtained by taking the mean of 50 data points of an index in the fault model, and calculating its difference from that of a healthy motor, 
followed by dividing the difference by the product of the difference $(\Delta)$ between the maximum and minimum values in the 50 data points of the same index in the fault model and that of a healthy motor.

Fault diagnosis in induction motors can be divided into two stages. The first is a preliminary classification of fault type through vibration detection, and the second is a further classification of fault type through electrical detection. The following is a description of the fast-screening fault diagnosis of the two stages.

In the first stage, the motor's acceleration signals along the three axes are acquired to calculate the statistical indices and peak values and to determine the corresponding thresholds. As the values for motors with stator and rotor faults are statistically closer to those for healthy motors, they are considered as belonging to the same fault group (Group 1). Bearing and misalignment faults are considered to belong to the same fault group (Group 2) because the index values for such motors are significantly higher than those for healthy motors. In summary, peak values can be used to roughly divide fault types into two groups.

The second stage is to acquire the motor's signals for the three-phase voltages and currents for determination of the electrical indices. According to the aforementioned suitability assessment, current unbalance rate (CUR), current unbalance factor (CUF), voltage total harmonic distortion (VTHD), each voltage harmonic distortion (EVHD), current total harmonic distortion (CTHD), and each current harmonic distortion (ECHD) are classified as either current imbalance electrical indices or harmonic distortion electrical indices for fast-screening fault diagnosis. If the result of the first stage is Group 1, then the screening rules for the second stage are as follows: If the electrical indices in both current imbalance and harmonic distortion are all lower than the international standard threshold, the motor is identified as healthy; if any electrical index in current imbalance exceeds the international standard threshold, it is identified as a stator fault; and if any electrical index in harmonic distortion exceeds the international standard threshold, it is identified as a rotor fault. As the fast-screening fault diagnosis is only based on a logic judgment of whether a value exceeds the threshold or not, it is unable to distinguish whether a fault occurs in the stator or rotor when electrical indices in both current imbalance and harmonic distortion exceed the threshold.

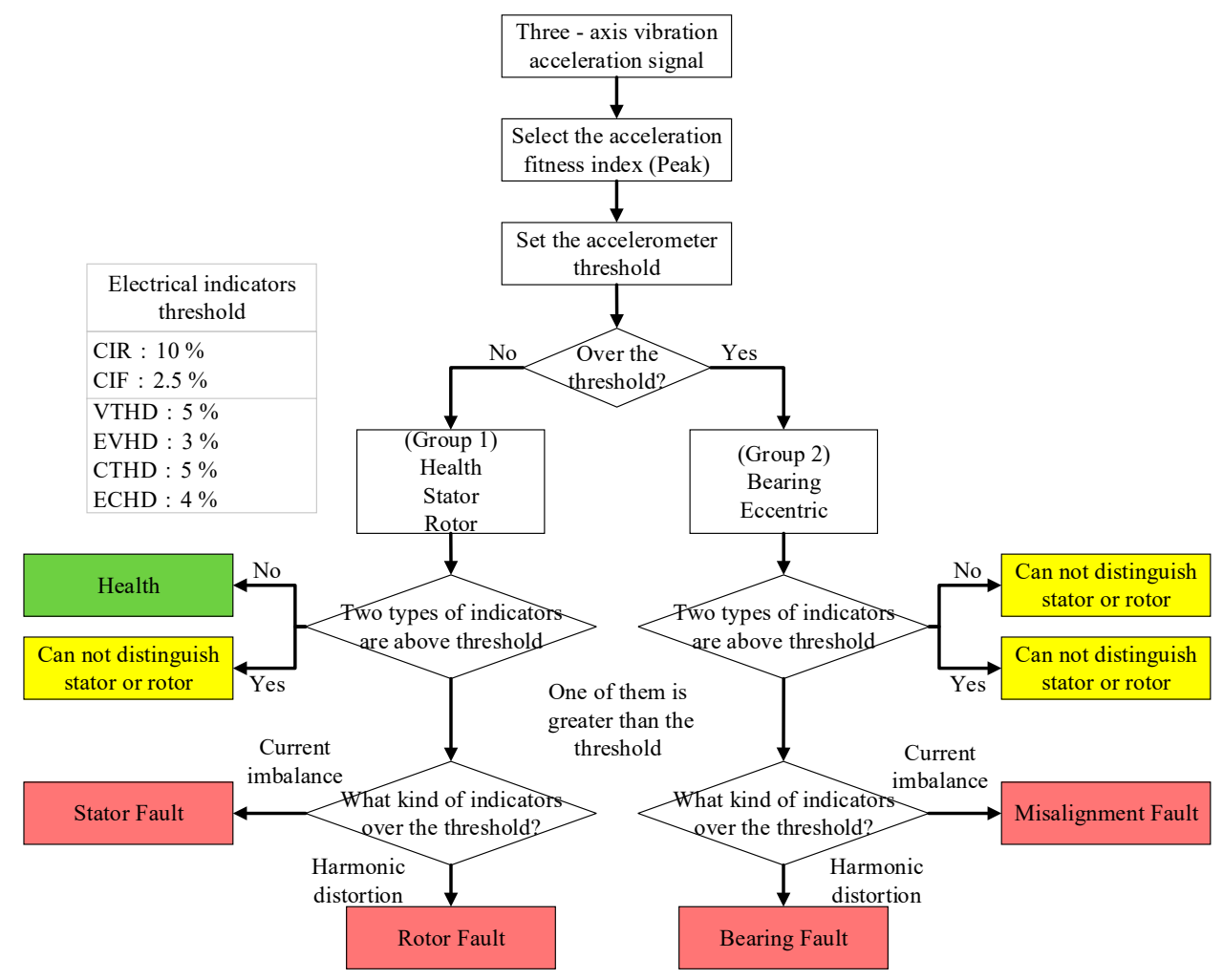

Figure 5. FDA module two-stage hybrid approach flow chart. 


\section{Experimental Results and Analysis}

\subsection{OCM Results and Analysis}

The rules are established based on two sets of international standards: ISO 10816-1 and NEMA MG-1. When the displacement is judged to be "Normal" according to NEMA MG-1, the velocity would be used to assess the level of operating condition as per IOS 10816-1; conversely, when the displacement is judged to be "Danger" as per NEMA MG-1, the operating condition would be rated as "Danger". The comprehensive results are shown in (Table 4).

Table 4. Operating condition monitoring rules.

\begin{tabular}{|c|c|c|c|c|}
\hline $\begin{array}{ll}\text { NEMA MG-1 } & \text { ISO 10816-1 } \\
\end{array}$ & Good & Acceptable & Unsatisfactory & Unacceptable \\
\hline Normal & Normal & Caution & Warning & Danger \\
\hline Danger & Danger & Danger & Danger & Danger \\
\hline
\end{tabular}

The feasibility assessment of the motor condition monitoring system requires longitudinal data. However, such data are lacking because the proposed system had not yet begun on-site testing. Hence, the feasibility of the proposed system is assessed using a vibration exciter in the laboratory to generate varying vibrations, the velocities, and displacements of which, after integral operations, is fast-screened to determine the operating conditions.

\subsection{FDA Results and Analysis}

To obtain standard sample data for the proposed fault diagnosis, this study used induction motors with identical specifications $(220 \mathrm{~V}, 7 \mathrm{~A}, 60 \mathrm{~Hz}, 2 \mathrm{HP}$, and four poles) to create four common fault models, and then used a healthy model for contrast. The experimental scale-down fault models are described as follows:

1. Stator fault: This fault occurs when the insulation layer of the stator coils is damaged by friction, aging, overheating, humidity, or corona. In the present study, a mild inter-coil short circuit is simulated by two coils short circuit after part of their insulation layer had been lightly scraped off (Figure 6a).

2. Rotor fault: If a motor is overloaded or restarted often, stress or heat buildup can cause the breakage of a rotor bar. This study consulted the literature and drilled a hole $7 \mathrm{~mm}$ in diameter and $30 \mathrm{~mm}$ in depth into the rotor bar (Figure 6b).

3. Bearing fault: The bearing outer ring is prone to damage when the motor is overloaded, overheated, or intruded by foreign objects. In this study, electric heating is applied to melt a hole in the bearing outer ring under the premise that the bearing and other components were not to be affected. The hole was $1 \mathrm{~mm}$ in diameter and depth (Figure 6c).

4. Misalignment fault: When the motor is with load, the coupling can cause misalignment at both ends due to human, environmental, or operational reasons, which in turn induces problems such as noise and heating. Because of safety considerations, the present study uses a healthy motor but displaced the coupling and load $0.5 \mathrm{~mm}$ upward (Figure $6 \mathrm{~d}$ ). 


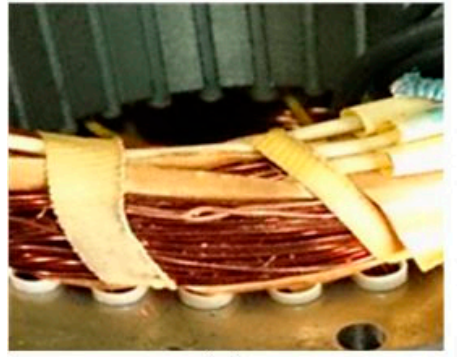

(a)

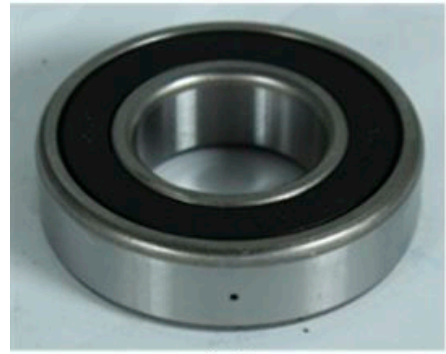

(c)

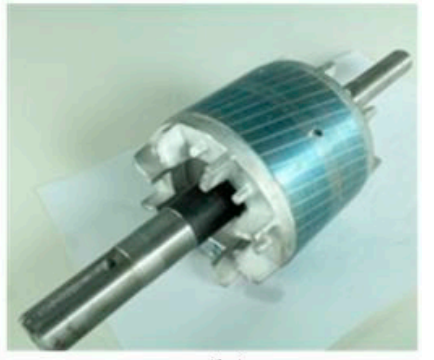

(b)

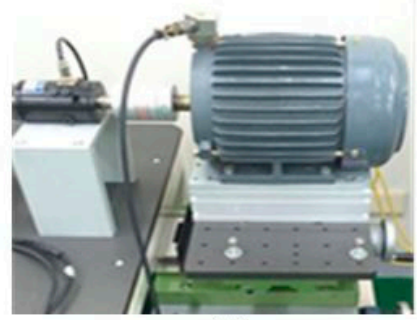

(d)

Figure 6. Four experimental models: (a) Stator fault, (b) rotor fault, (c) bearing fault, (d) misalignment fault.

To verify the effectiveness of the proposed system, the aforementioned stator interturn short circuit, rotor bar breaking, bearing outer ring damage, and misalignment fault models and a healthy motor were employed for measurement. The sampling rate was $10 \mathrm{kHz}$, and 50 data entries were taken for each motor, amounting to 250 data points in total. The data were used to compare the diagnostic results when electrical detection alone was employed and the proposed hybrid approach of combining vibration detection and electrical detection was used. From the results of Table 5, it is shown that the five experimental models can be effectively distinguished using the hybrid approach.

Table 5. FDA results classification accuracy (\%).

\begin{tabular}{ccccccc}
\hline Fault Type & Diagnosis & H & S & $\mathbf{R}$ & $\mathbf{B}$ & $\mathbf{M}$ \\
\hline H & 100 & 0 & 0 & 0 & 0 \\
S & 0 & 100 & 0 & 0 & $44^{* 1}$ \\
R & 0 & 0 & 100 & 0 & 0 \\
B & 0 & 0 & 0 & 100 & 0 \\
M & 0 & 0 & 0 & 0 & $96^{* 1}$ \\
& & & & & & $100^{* 2}$
\end{tabular}

H: Health, S: Stator, R: Rotor, B: Bearing, M: Misalignment; ${ }^{* 1}$ : Electrical approach; ${ }^{* 2}$ : Hybrid approach.

Table 6 presents the testing results of the samples, suggesting that electrical detection alone and the proposed hybrid approach are both able to accurately identify the healthy motor and the stator, rotor, and bearing faults; however, for misalignment faults, electrical detection identified $20.76 \%$ as misalignment faults and misidentified $37.85 \%$ as stator faults. By contrast, the proposed hybrid approach was able to accurately identify misalignment faults. For each individual model, the hybrid approach was superior to electrical detection in fault diagnosis. For example, the hybrid approach was able to identify $56.21 \%$ of stator faults whereas electrical detection was only able to identify $37.85 \%$. 
Table 6. FDA results classification accuracy (\%).

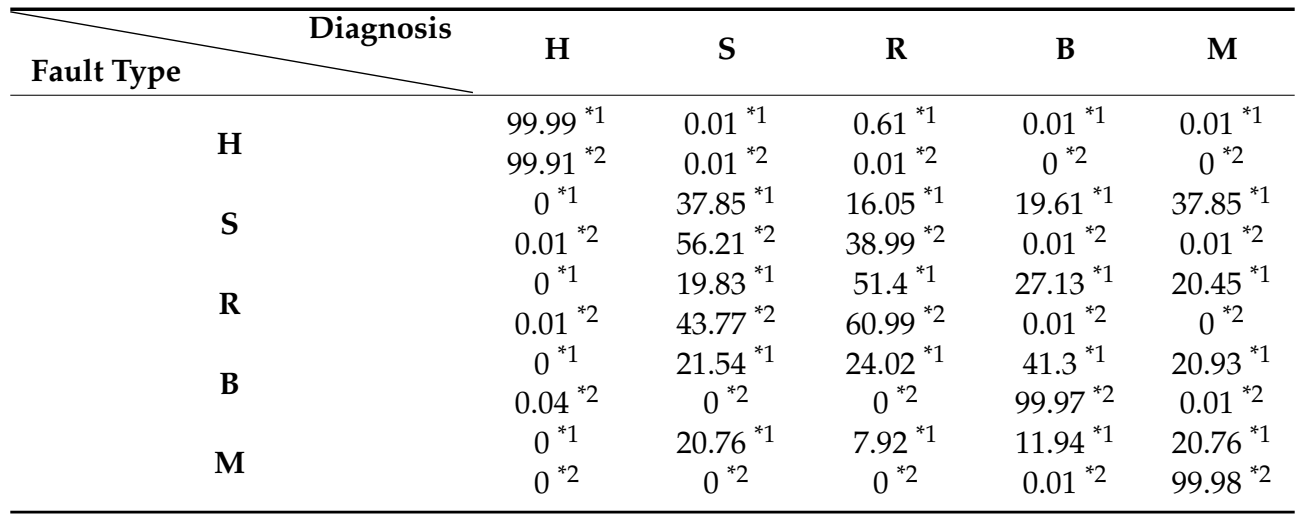

H: Health, S: Stator, R: Rotor, B: Bearing, M: Misalignment; ${ }^{* 1}$ : Electrical approach; ${ }^{* 2}$ : Hybrid approach.

\section{Conclusions}

The present study successfully develops a condition-based system which can monitor various types of motor faults by using the proposed vibration-electrical hybrid approach. The system uses vibration detection for operating condition monitoring in accordance with rules drawn from the ISO 10816-1 and NEMA MG-1 standards. Laboratory test results indicate that the system can correctly monitor the operating conditions of a motor as per the rules. For fault diagnosis analysis, the system uses vibration detection and electrical detection for fault classification. The results of laboratory tests show that the classification accuracy of the proposed hybrid system is superior to that of the electrical approach to fault type identification. Additionally, the system is able to issue simple and clear instructions, which is a substantial improvement on existing systems and highly convenient for on-site personnel.

Author Contributions: Conceptualization, H.-C.C. and C.-C.K.; methodology, H.-C.C. and C.-C.K.; software, Y.-M.J. and Y.-M.H.; validation, Y.-M.J. and Y.-M.H.; data curation, H.-C.C.; writing-original draft preparation, Y.-M.J.

Funding: MOST-105-2221-E-011-081-MY3.

Acknowledgments: This paper supports the research funding of the Ministry of Science and Technology, Taiwan under Grant MOST-105-2221-E-011-081-MY3 is gratefully acknowledged.

Conflicts of Interest: The authors declare no conflict of interest.

\section{References}

1. Maitre, J.; Bouchard, B.; Bouzouane, A.; Gaboury, S. Classification Algorithms Comparison for Interturn Short-Circuit Recognition in Induction Machines Using Best-Fit 3-D-Ellipse Method. Can. J. Electr. Comput. Eng. 2017, 40, 255-265.

2. Hou, Z.; Huang, J.; Liu, H.; Ye, M.; Liu, Z.; Yang, J. Diagnosis of broken rotor bar fault in open- and closed-loop controlled wye-connected induction motors using zero-sequence voltage. IET Electr. Power Appl. 2017, 11, 1214-1223. [CrossRef]

3. Boudinar, A.H.; Benouzza, N.; Bendiabdellah, A. Induction Motor Bearing Fault Analysis Using a Root-MUSIC Method. IEEE Trans. Ind. Appl. 2016, 52, 3851-3860. [CrossRef]

4. Antonino-Daviu, J.A.; Arkkio, A.; Georgoulas, G.; Climente-Alarcon, V.; Tsoumas, I.P.; Stylios, C.D.; Nikolakopoulos, G. The Use of a Multilabel Classification Framework for the Detection of Broken Bars and Mixed Eccentricity Faults Based on the Start-Up Transient. IEEE Trans. Ind. Inform. 2017, 13, 625-634.

5. Zhang, P.; Du, Y.; Habetler, T.G.; Lu, B. A Survey of Condition Monitoring and Protection Methods for Medium-Voltage Induction Motors. IEEE Trans. Ind. Appl. 2011, 47, 34-46. [CrossRef]

6. Mahmoud, H.; Abdallh, A.A.; Bianchi, N.; El-Hakim, S.M.; Shaltout, A.; Dupré, L. An Inverse Approach for Inter-Turn Fault Detection in Asynchronous Machines Using Magnetic Pendulous Oscillation Technique. IEEE Trans. Ind. Appl. 2016, 52, 226-233. [CrossRef] 
7. Ghanbari, T. Autocorrelation function-based technique for stator turn-fault detection of induction motor. IET Sci. Meas. Technol. 2016, 10, 100-110. [CrossRef]

8. Drif, M.; Cardoso, A.J.M. Stator Fault Diagnostics in Squirrel Cage Three-Phase Induction Motor Drives Using the Instantaneous Active and Reactive Power Signature Analyses. IEEE Trans. Ind. Inform. 2014, 10, 1348-1360. [CrossRef]

9. Duan, F.; Živanović, R. Condition Monitoring of an Induction Motor Stator Windings Via Global Optimization Based on the Hyperbolic Cross Points. IEEE Trans. Ind. Electron. 2015, 62, 1826-1834. [CrossRef]

10. Urresty, J.-C.; Ruiz, J.-R.R.; Romeral, L. Influence of the Stator Windings Configuration in the Currents and Zero-Sequence Voltage Harmonics in Permanent Magnet Synchronous Motors With Demagnetization Faults. IEEE Trans. Magn. 2013, 49, 4885-4893. [CrossRef]

11. Faiz, J.; Nejadi-Koti, H.; Valipour, Z. Comprehensive review on inter-turn fault indexes in permanent magnet motors. IET Electr. Appl. 2017, 11, 142-156. [CrossRef]

12. Abdallah, H.; Benatman, K. Stator winding inter-turn short-circuit detection in induction motors by parameter identification. IET Electr. Appl. 2017, 11, 272-288. [CrossRef]

13. Rangel-Magdaleno, J.D.J.; Peregrina-Barreto, H.; Ramirez-Cortes, J.M.; Gomez-Gil, P.; Morales-Caporal, R. FPGA-Based Broken Bars Detection on Induction Motors Under Different Load Using Motor Current Signature Analysis and Mathematical Morphology. IEEE Trans. Instrum. Meas. 2014, 63, 1032-1040. [CrossRef]

14. Gritli, Y.; Bin Lee, S.; Filippetti, F.; Zarri, L. Advanced Diagnosis of Outer Cage Damage in Double-Squirrel-Cage Induction Motors Under Time-Varying Conditions Based on Wavelet Analysis. IEEE Trans. Ind. Appl. 2014, 50, 1791-1800. [CrossRef]

15. Kang, T.-J.; Kim, J.; Bin Lee, S.; Yung, C. Experimental Evaluation of Low-Voltage Offline Testing for Induction Motor Rotor Fault Diagnostics. IEEE Trans. Ind. Appl. 2015, 51, 1375-1384. [CrossRef]

16. Godoy, W.F.; Da Silva, I.N.; Lopes, T.D.; Goedtel, A.; Palácios, R.H.C. Application of intelligent tools to detect and classify broken rotor bars in three-phase induction motors fed by an inverter. IET Electr. Appl. 2016, 10, 430-439. [CrossRef]

17. Frosini, L.; Harlisca, C.; Szabó, L. Induction Machine Bearing Fault Detection by Means of Statistical Processing of the Stray Flux Measurement. IEEE Trans. Ind. Electron. 2015, 62, 1846-1854. [CrossRef]

18. Prieto, M.D.; Cirrincione, G.; Espinosa, A.G.; Ortega, J.A.; Henao, H. Bearing Fault Detection by a Novel Condition-Monitoring Scheme Based on Statistical-Time Features and Neural Networks. IEEE Trans. Ind. Electron. 2013, 60, 3398-3407. [CrossRef]

19. Sousa, K.M.; Dreyer, U.J.; Martelli, C.; Da Silva, J.C.C. Dynamic Eccentricity Induced in Induction Motor Detected by Optical Fiber Bragg Grating Strain Sensors. IEEE Sens. J. 2016, 16, 4786-4792. [CrossRef]

20. Ebrahimi, B.M.; Roshtkhari, M.J.; Faiz, J.; Khatami, S.V. Advanced Eccentricity Fault Recognition in Permanent Magnet Synchronous Motors Using Stator Current Signature Analysis. IEEE Trans. Ind. Electron. 2014, 61, 2041-2052. [CrossRef]

21. Yahia, K.; Sahraoui, M.; Ghoggal, A.; Cardoso, A.J. The Use of a Modified Prony's Method to Detect the Airgap-Eccentricity Occurrence in Induction Motors. IEEE Trans. Ind. Appl. 2016, 52, 3869-3877. [CrossRef]

22. Ojaghi, M.; Aghmasheh, R.; Sabouri, M. Model-based exact technique to identify type and degree of eccentricity faults in induction motors. IET Electr. Appl. 2016, 10, 706-713. [CrossRef]

23. Fischer, K.; Coronado, D.A. Condition Monitoring of Wind Turbines: State of the Art, User Experience and Recommendation; Fraunhofer Institute for Wind Energy and Energy System Technology IWES: Bremerhaven, Germany, January 2015; pp. 51-56.

24. ISO 10816-1. Mechanical Vibration-Evaluation of Machine Vibration by Measurements on Non-Rotating Parts_Part 1: General Guidelines; ISO: Geneva, Switzerland, 1995.

25. NEMA MG-1. Motors and Generators; NEMA: Rosslyn, VI, USA, 2009.

26. Lin, S.C.; Chang, H.C.; Kuo, C.C.; Hsu, T.C.; Shen, W.C. Assessment of Motor Conditions Using Electrical and Vibrational Detection Methods. In Proceedings of the International Conference on Engineering and Natural Science, Tokyo, Japan, 22-24 July 2015; pp. 41-58.

27. IEC 60034-1. Rotating Electrical Machines_Part 1: Rating and Performance; IEC: Geneva, Switzerland, 2010.

28. ANSI/IEEE Std. IEEE Recommended Practice for Electric Power Distribution for Industrial Plants; ANSI/IEEE Std.: New York, NY, USA, 1993. 
29. IEEE Std. 519. IEEE Recommended Practices and Requirements for Harmonic Control in Electrical Power Systems; IEEE Std.: New York, NY, USA, 1992.

() 1 (C) 2019 by the authors. Licensee MDPI, Basel, Switzerland. This article is an open access article distributed under the terms and conditions of the Creative Commons Attribution (CC BY) license (http://creativecommons.org/licenses/by/4.0/). 